\title{
Pedaling toward the future: Increasing and maintaining the school attendance of adolescent girls in indigenous communities of rural Guatemala
}

Paola Broll

Population Council

Follow this and additional works at: https://knowledgecommons.popcouncil.org/departments_sbsr-pgy

Part of the Demography, Population, and Ecology Commons, Family, Life Course, and Society Commons, Gender and Sexuality Commons, and the International Public Health Commons How does access to this work benefit you? Let us know!

\section{Recommended Citation}

Broll, Paola. 2018. "Pedaling toward the future: Increasing and maintaining the school attendance of adolescent girls in indigenous communities of rural Guatemala," brief. Guatemala City: Population Council. 


\section{PEDALING TOWARD THE FUTURE:}

INCREASING AND MAINTAINING THE SCHOOL ATTENDANCE OF ADOLESCENT GIRLS IN INDIGENOUS COMMUNITIES OF RURAL GUATEMALA

PAOLA BROLL

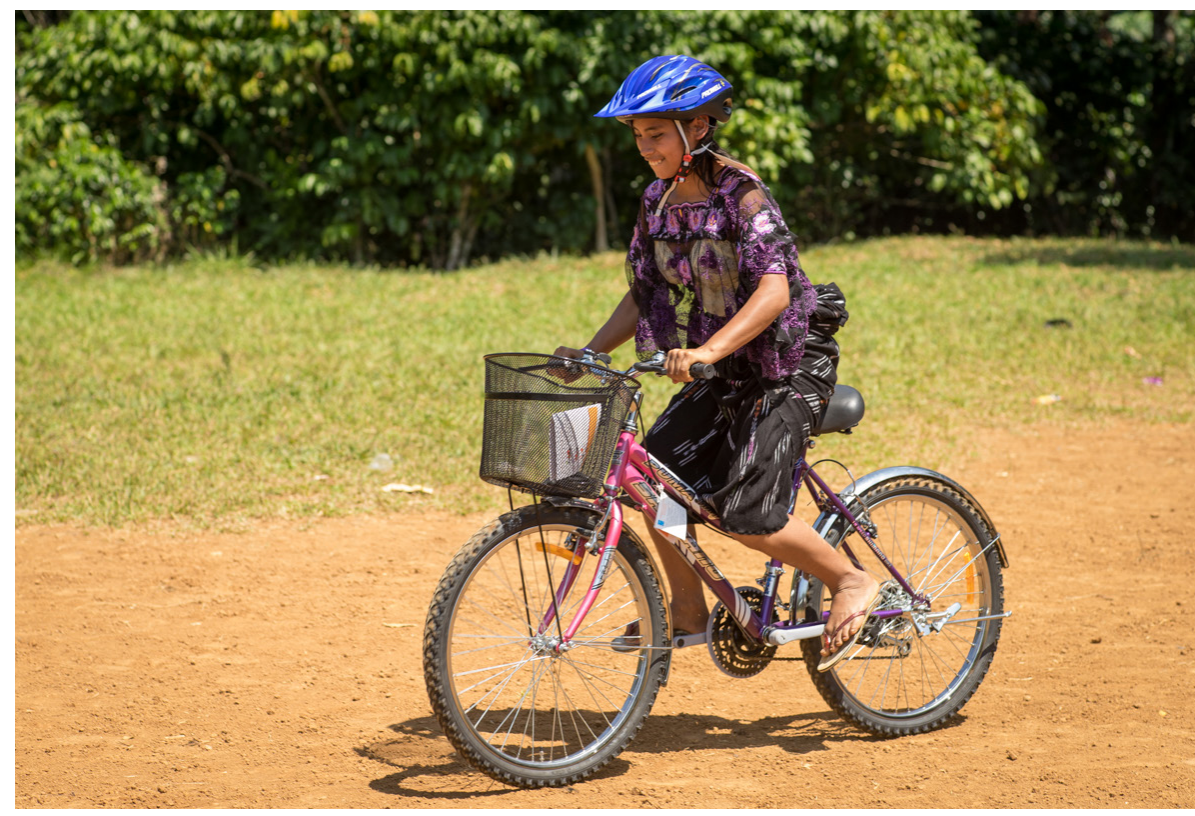

A participant from Pecajbá, Chisec, Alta Verapaz on the way to secondary school, a distance of $7 \mathrm{~km}$ (4 mi) from her house.

Population Council Guatemala, with the support of UNFPA and other donors, developed a strategy of expansion and scale-up of Abriendo Oportunidades (AO) through geographic conglomerates with an ecological approach. AO was implemented in four municipalities: Chisec (Alta Verapaz), Dolores, Poptún (Petén), and San Luis, reaching 4,425 participants. The provision of 250 bicycles was an additional component of AO to assess its effectiveness in increasing mobility and school attendance from November 2016 to October 2017 in the four municipalities. The bicycles were delivered to 30 communities that do not have secondary schools.

The Population Council is an international, nonprofit, nongovernmental organization that conducts research and delivers solutions to improve lives around the world. The research carried out by the Population Council in Guatemala showed that social programs systematically fail to reach the most vulnerable populations because they are not specifically designed to meet the needs of these groups. ${ }^{1}$

\section{MAIN RESULTS}

1. The provision of 250 bicycles to adolescents participating in the Abriendo Oportunidades program increased school reintegration from the 2016 cycle to the 2017 cycle by $24 \%$.

2. $97 \%$ of participants completed the 2017 school year.

3. Intention to study among the 250 participants increased from $76 \%$ (2017 school year) to $97 \%$ (2018 school year).

4. Adolescents want to continue studying when they have a means of transportation that facilitates their mobility to the nearest study center.

5. $51 \%$ of participants increased their mobility with the bicycle.

6. The increase in mobility with the bicycles allowed participants to continue their secondary studies, occupy public spaces of commercial exchange, strengthen their social capital, and have access to recreational activities.

\footnotetext{
${ }^{1}$ The Adolescent Experience In-Depth: Using Data to Identify and Reach the Most Vulnerable Young People: Guatemala 2002/2006. New York: Population Council, 2009.

http://www.popcouncil.org/uploads/pdfs/PGY_AdoIDataGuides/Guatemala2002-06.pdf.
}

The Population Council conducts research and delivers solutions that improve lives around the world. Big ideas supported by evidence:

It's our model for global change. popcouncil.org

(c) 2018 The Population Council, Inc. 
In response, the Population Council created the Abriendo Oportunidades program to reach indigenous adolescent girls at the highest levels of vulnerability in rural communities in Guatemala. ${ }^{2}$ Since 2004, AO has trained groups of adolescent girls, divided by age, who meet once a week in a safe space to carry out sessions from the AO Curriculum Guide. ${ }^{3}$ The sessions are facilitated by mentors who are women from the same communities between 18 and 24 years old who become agents of social change. The result of this effort is an increase in the self-esteem of the participants; the leadership instinct of girls, adolescents, and women; and the promotion of gender equality. ${ }^{4}$

AO engages community leaders, increases the social support networks of adolescent girls, and connects girls with alternative models of mentors with whom they learn practical skills that prepare them for the transition to adulthood and the assumption of leadership roles. For UNFPA it is a priority to reach marginalized and disadvantaged adolescents and young people, especially girls, because millions of them live in extreme poverty. The Action for Adolescent Girls (AAG) initiative of UNFPA supported working in a focused and integrated way for the benefit of adolescent girls at risk of child marriage and early pregnancy.

\section{ACTIVITIES AND RESULTS}

In November 2016, 1,188 AO participants reviewed the Life Plan session. In this session each adolescent establishes five goals for her life in the personal, family, study/work, economic, and community areas. The goals are defined in the short, medium, and long term and presented in a meeting with mothers, fathers, and local authorities. A review of the Life Plans indicated that of the 1,188 participants, 976 (82\%) had studied in 2016 and 212 (18\%) had not (Figure

1). The criteria for selecting a participant to receive a bicycle were the following:

1. Distance from the participant's home to the nearest study center;

2. Means of transportation from the participant's home to the nearest study center;

3. Cost of transportation from the participant's home to the nearest study center; and

4. Time spent on walking, if applicable, from the participant's home to the nearest study center.

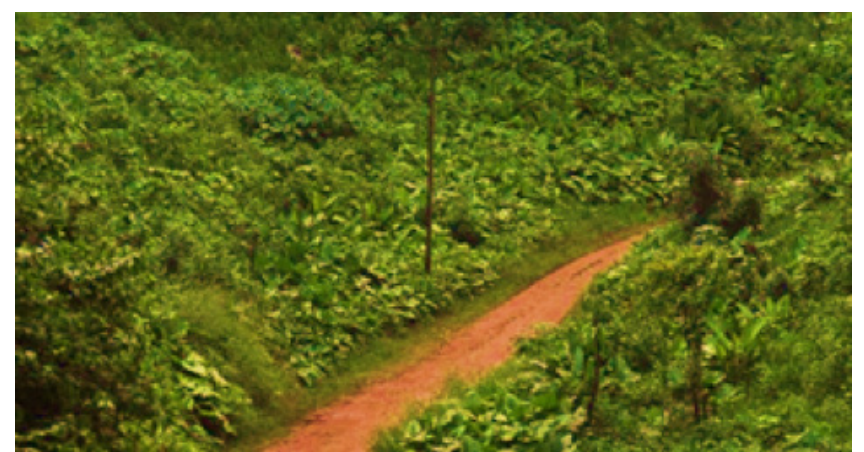

The roads of the rural area are, for the most part, solitary dirt roads surrounded by crops. Participants travel - on average $-10 \mathrm{~km}(6 \mathrm{mi})$ per day to study at a community school or extra-school education center.

FIGURE 1. PERCENTAGE OF THE 1,188 AO

PARTICIPANTS WHO STUDIED IN 2016

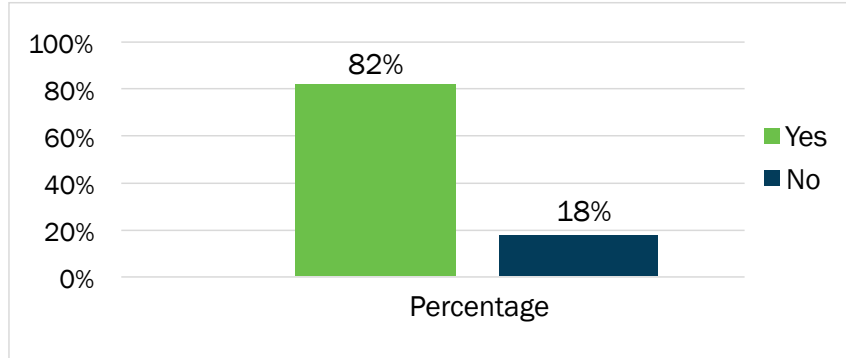

Source: AO Monitoring Database, Life Plan Session, November 2016.

FIGURE 2. PERCENTAGE OF THE 250 PARTICIPANTS SELECTED TO RECEIVE A BICYCLE WHO INTEND TO STUDY DURING THE 2017 SCHOOL YEAR

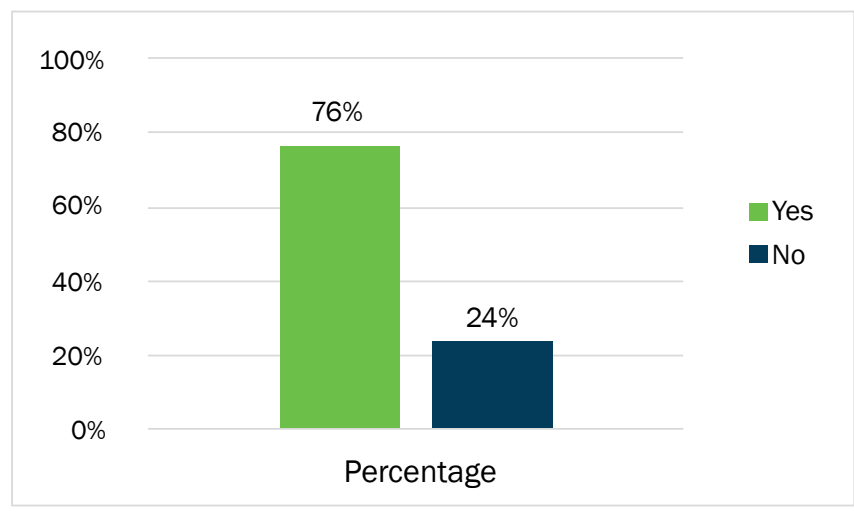

Source: AO Monitoring Database, Life Plan Session, November 2016.

\footnotetext{
${ }^{2}$ https://www.girlsnotbrides.org/wp-content/uploads/2016/02/Case-Study-Empower-girls-Population-Council-Guatemala.pdf.

${ }^{3}$ http://www.popcouncil.org/research/abriendo-oportunidades-program-integrated-curriculum-guide.

${ }^{4}$ Cushman, Nicole. 2010. Guatemala rising, one girl at a time. Findings from the 2009-2010 Abriendo Oportunidades evaluation. EEUU: Population Council.
} 
Of the 212 participants who did not study in 2016, 59 met the selection criteria but said they had no intention of studying in 2017 because of a lack of economic resources and the distance required to reach the study center. During the monitoring visits of November and December 2016, the possibility was explored, through home visits, of reintegrating into secondary studies $24 \%$ (59) of the 250 selected to receive bicycles; the other 191 participants (76\%) indicated that they intended to study during the 2017 school year (Figure 2). Delivery of the 250 bicycles (228 in Alta Verapaz and 22 in Petén) was in February and March of 2017, coinciding with registration for the 2017 school year, resulting in the achievement of $100 \%$ registration among the participants in the project.

The Population Council team monitored activities monthly with the support of four mentors in the field. In Alta Verapaz, 30 communities were visited with 5 secondary schools and 10 Flexible Modalities Program study centers. In Petén, 20 communities were visited with one Flexible Modalities Program study center. There was monthly monitoring of progress in the girls' studies: the challenges they faced by having bicycles; the places they visited-inside and outside of their community-and the purpose of visits made by bicycle; the people who used the bicycle; whether a girl ever wanted to use the bicycle but could not because someone else had it; the expenses incurred in repairing the bicycle; and the reasons for dropping out of school.

The participants never knew the day they would be visited at the study center. $97 \%$ of them were present in the study center during $100 \%$ of the monitoring visits. The other $3 \%$ (8 participants) were absent, eventually giving up school due to marrriage (3), migration (2), pregnancy (2), and family chores (1).

The monitoring data show that the proportion of participants who intended to study changed from $76 \%$ for the 2017 cycle to $97 \%$ for the 2018 cycle (Figure 3). With these data we can infer that having a means of transportation that facilitates mobility in reaching the study center encourages the young women to continue their studies.

At the beginning of the project, $49 \%$ reported moving in or out of the community. At the end of the project, $100 \%$ reported some type of mobility. Information gathered during the monitoring indicated that participants increased their mobility by $11 \%$ within and $37 \%$ outside their communities
FIGURE 3. COMPARISON OF PERCENTAGE OF INTENTION TO STUDY AMONG THE 250 PARTICIPANTS FOR THE 2017 AND 2018 SCHOOL YEARS

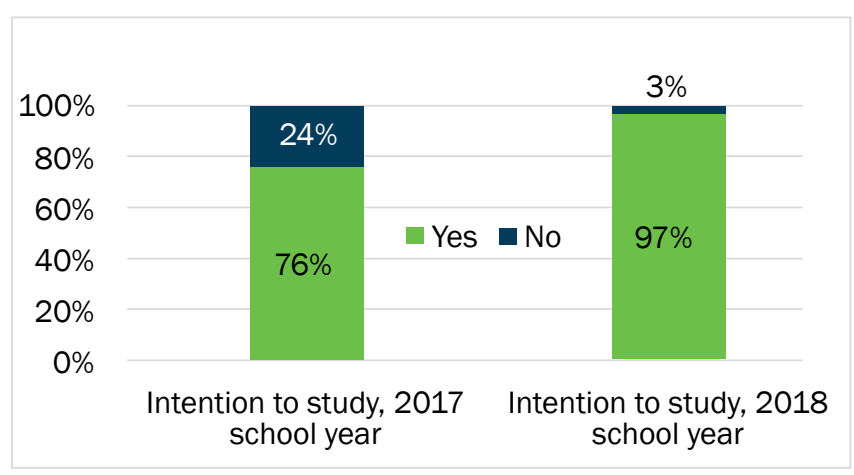

Source: AO Monitoring Database, October 2017.

FIGURE 4. COMPARISON OF PERCENTAGES OF MOBILITY WITHIN AND OUTSIDE THE COMMUNITY, AT THE BEGINNING AND END OF THE PROJECT

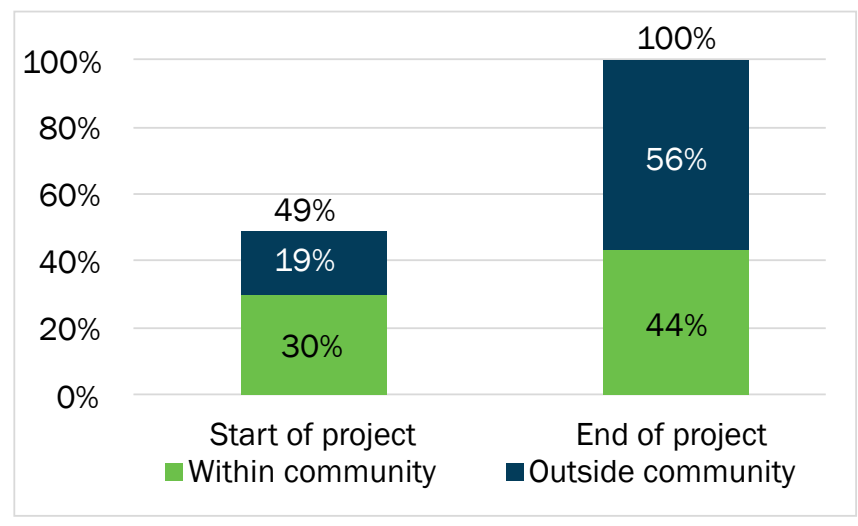

Source: AO Monitoring Database, October 2017.

FIGURE 5. COMPARISON OF PERCENTAGES OF THE PLACES MOST VISITED BY BICYCLE OF THE 250 PARTICIPANTS

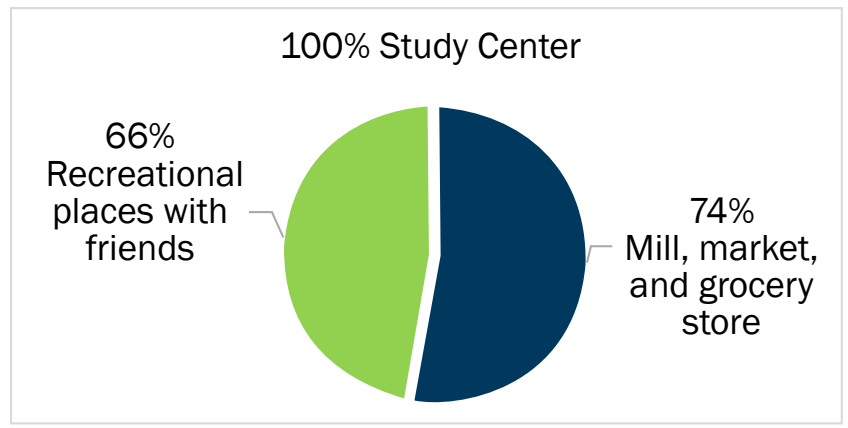

Source: AO Monitoring Database, October 2017. 
(Figure 4). 74\% of participants indicated that they traveled to places that represent economic activities related to household tasks, such as the mill, the market, and the grocery store. $66 \%$ agreed that the bicycle helped them to be able to visit their friends, strengthening their support network and social capital in recreational activities such as playing ball or swimming in the river (Figure 5).

The majority reported that they had to hide their bike from the entrance to the study center so that their male classmates would not take it from them. Many had to lend it to their parents and siblings and had to make sure it was available to get to the study center.

\section{CONCLUSIONS AND RECOMMENDATION}

1. The long and dangerous distances that adolescents travel on foot to reach a center of secondary education promote school absenteeism and the abandonment of studies.

2. The project was successful in increasing mobility, reinsertion, and completion of the 2017 school year among its participants.

3. The project demonstrated success by increasing the intention to study from $76 \%$ (2017 school year) to $97 \%$ (2018 school year).

4. In communities where bicycles were delivered, women had never had their own means of transportation. Receiving a bicycle opened opportunities for the project participants to go to the nearest study center, visit neighboring communities for economic activities, and enjoy recreational activities with friends.

5. In Chisec, Alta Verapaz, the national retention rate of the school system for 2016 was $79.8 \% .^{5}$ The project achieved a retention rate of $98 \%$; of the 228 participants only 4 abandoned their studies.

6. The project achieved a retention rate of $75 \%$, noting that the participants studied in the after-school system which does not have national retention data.

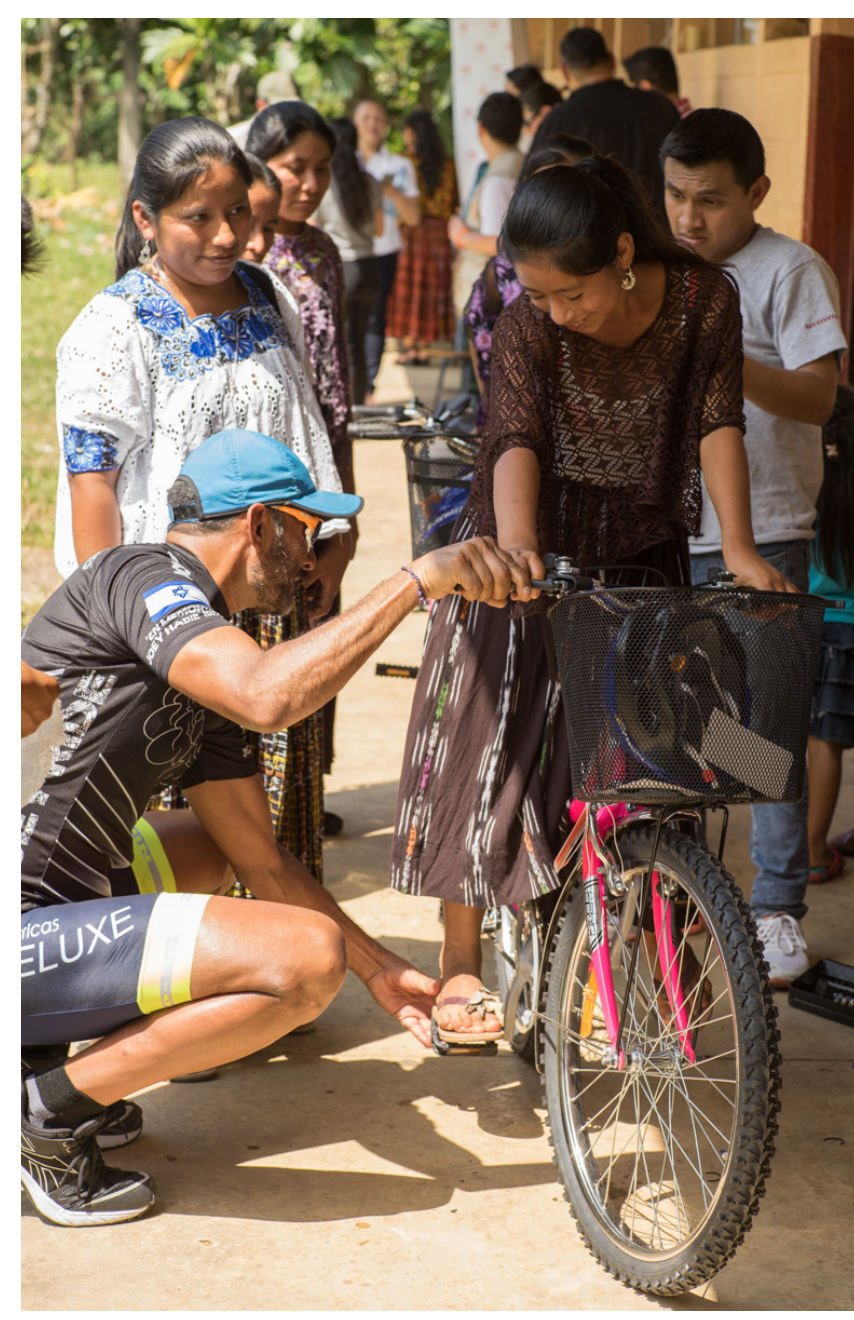

A young woman receives one of the 250 bicycles provided through the Abriendo Oportunidades program.

\footnotetext{
${ }^{5}$ http://estadistica.mineduc.gob.gt/SNIE/eficiencia.html.
} 